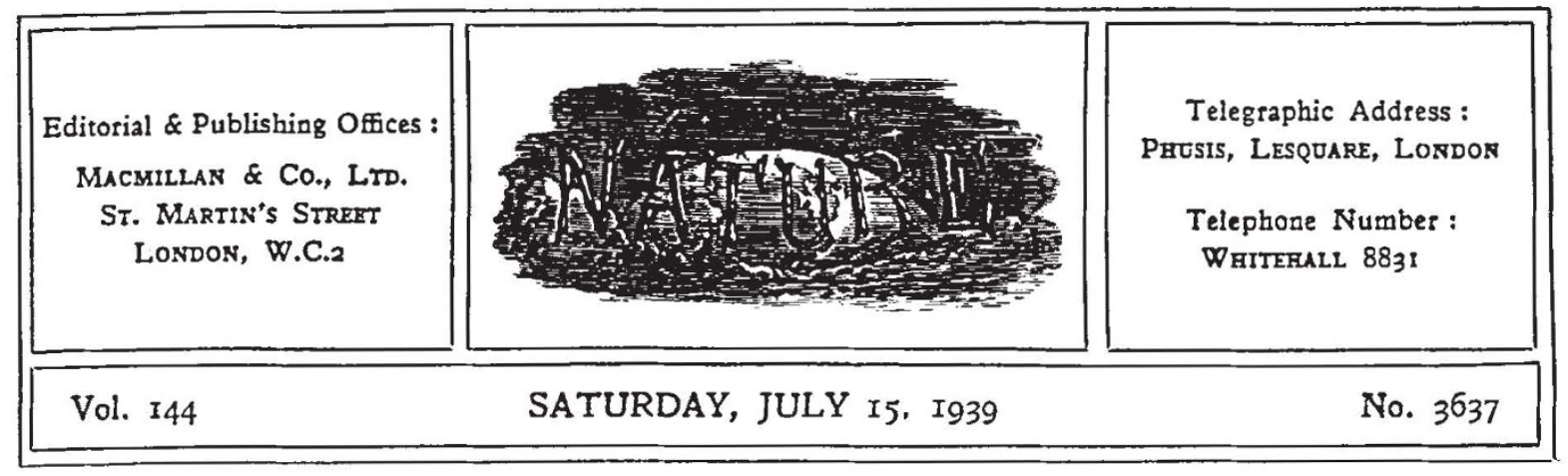

\title{
THE MUSEUM AND THE SCHOOL
}

W ITH commendable restraint those responsible for the organization of the exhibition of museum publications of educational interest, which was held at University College, London, during June 20-July 15, made no attempt at exhaustive or elaborate display. It was a sampling, for which the material was derived from London and from certain museums of the United States of America. The English contributors included, in addition to the national collections, the London Museum and one of the museums of the London County Council-the Geffrye Museum. Modest as was this effort, it served the purpose, as no doubt was the intention, of provoking thought. The contrast here presented between the methods of the English and the American museums inevitably gave rise to reflection as to the purpose of these great collections of objects of natural, scientific and historic interest, of beauty and of rarity, and the nature of the function which they perform, or might perform, in the life of a community.

As Lord Bledisloe said in his address to the jubilee gathering of the Museums Association, the museum in its original conception was " $a$ fountain of culture alike for young and old, for rich and poor, for layman and expert, adapted to the everyday intellectual and spiritual requirements of the nation as a whole". Without venturing to question the historical accuracy of this statement, we may concur in Lord Bledisloe's dictum and agree with him when he went on to point out, coupling the cinema with the museum, that "as the eye is the most efficacious channel of entry into the mind, there are no more promising educational agents or more powerful stimulants to the imagination than the museum and the cinema". But at the same time, as every educationist is aware, it must not be overlooked that visual impression, whether in adult or child, is but fleeting, unless it finds the mind of the observer already prepared to receive it, and able to link it to material which the mind has already made its own. It is by the nature and the extent of the museum's co-operation with the observer in storing up such a body of assimilated fact that the performance of its educational function must be judged.

In all the important London museums and collections, the institution of guide-lecturers, of special exhibitions, permanent or temporary, illustrating some special phase or problem, and a ready hospitality extended to school visits, have done much to make the public familiar with the character and meaning of the objects in these collections. The services of the lecturers, however, are available for comparatively few of the museum's visitors-those who have the leisure and the opportunity to attend at stated times. For the majority, or at any rate a large proportion, more intimate and more intensive study than is possible in a perambulation of the galleries, even the occasion for arousing interest and stimulating study, must depend to a great extent upon the museum publications. Within the limited space of the exhibition room at University College has been shown a selection of these publications. It was headed by some of the attractive and sometimes striking posters directing attention to the collections in the various museums, which are displayed by the London Passenger Transport Board. Each of these posters, artistic and brightly, but not garishly, coloured, is characteristic of the collection which it announces. The second, an extensive exhibit, consisted of the long range of 
picture post-cards and reproductions, mostly in colour, which illustrate almost every branch of science, art and history susceptible of demonstration in a museum.

Of the museum publications in book form, the more technical and advanced did not come within the scope of an exhibition intended to consider only the needs of schools, and the selection shown was confined to the simpler and more popular guides, which do, in fact, carry further the interest aroused by the collections themselves, or by the post-card series. Such a development of interest is to be noted, for example, in the Science Museum series, dealing with topics such as the development of transport, locomotion, navigation, aeronautics and the like.

Reviewing the exhibits from the English museums as a whole, and as an instrument of instruction, the more striking features are the care which has been lavished on the selection and preparation of the various series, the care in production and reproduction, and the scholarship and knowledge which have been drawn upon freely to make known to the general public the character and meaning-scientific, æsthetic or historical-of the wealth of objects displayed in London's museums. It must be apparent, however, that in so far as this material was brought together to illustrate the educational interest of museum publications, it shows strikingly little effort to make readily available for the school a vast amount of material of immense educational value. Except for the Geffrye Museum, which, with the Horniman Museum at Forest Hill, is part of London's educational organization, there is no direct orientation towards the needs of the school. It is here that the contrast with the American museum becomes marked.

Exhibits were shown from five of the larger American museums: the Metropolitan Nuseum of New York, Boston Museum of Fine Arts and the Brooklyn, Buffalo and Cleveland Museums. It is made abundantly evident that each of these museums regards itself, even if this be not explicitly stated in the terms of its founda. tion, as having a specific function in the cultural life and educational system of the region in which it stands. Normally, it has an educational division, section or committee, and an educational staff; and it undertakes organized educational work. There is a carefully prepared system of preparatory propaganda. Post-cards, memoranda, and pro. grammes are circulated among the heads of primary, secondary and technical schools and other educational institutions. In some museums, courses are specially arranged to fit in with the curricula, after consultation with the staffs of primary, secondary, and technical schools. They are given by members of the museum staff in special rooms. The museum educational staff is available for consultation by teachers and others interested in education, sometimes at a small fee.

Finally, there are the museum publications, usually a museum journal, which, in addition to notes on recent acquisitions, will contain articles on special groups of exhibits; or, in those museums which specialize in art, dealing with the work of a painter or sculptor, or like topic of artistic or antiquarian interest; while some museums publish a periodical devoted entirely to the interests of school children, and dealing with Nature studies, hobbies and the like. Of a more specifically educational character are sheets or cards of grouped illustrative material, with notes prepared by the museum staff. These are circulated for instructional purposes among the schools. There are also special publications, usually in pamphlet form, or guides dealing with grouped exhibits or special collections.

In general, it may be said that the material which is thus circulated among the schools or made available for their use is scarcely comparable in its printing or general technical character with the publications of English museums, nor, it may be said without offence, does it show the same standard of scholarship. At the same time, it has to be admitted that, having been prepared for a specific purpose and with the educational end in view, it is more certain to reach its mark.

It was abundantly apparent in the material shown at University College that the American museum has not shrunk from taking what it has regarded as its educational responsibility very seriously. This is due in part, of course, to the fact that, whereas the British national and other important collections, owing to their origin, have assumed the character of storehouses of national treasures, and their connexion with the advancement of knowledge has been almost entirely by way of research and not of instruction, in the United States the museums have been founded as, or have become, part of the cultural equipment of the region each serves. Most of them, too, are dependent for their current expenses, not on their 
endowment or on support from public funds, but on fees and membership subscriptions; the extent of membership is reflected by the degree in which the activities of the museum meet the cultural needs of its area.

The English institution more nearly comparable with the American museum is the local provincial museum, which grew out of the interests of the local literary, philosophical or antiquarian society. When communications were less casy and other distractions less numerous than they are now, this served as a social and cultural focus for its neighbourhood. Its educational function might well be revived, where it has lapsed, and extended.

While the very different conditions which affect our large museums, in contrast with those affecting American museums, must be recognized, yet a comparison of the two systems of organization in Great Britain and in the United States gives rise to an uneasy feeling that the most is not made in education of the wealth of scientific and cultural material that is available in collections in Great Britain. If it be pointed out in extenuation that a remarkable range of illustrative material from which to select is available for the teacher, the reply surely must be that the teacher is not a specialist; and simple and even elementary as much of the detail in the museum guides and other publications may seem to the specialist, for the layman, however intelligent, they make stiff and uphill reading. The classes and lectures for teachers at the Horniman Museum, and the appointment of liaison officers between school and museum on the inspectorate of the London County Council, were steps in the right direction; but they do not go far enough. To be of lasting value, museum material must be brought into intimate relation with the school curriculum. Intermittent visits to general collections have little permanent instructional value. To suggest that special exhibitions should be arranged in special rooms to meet the needs of schools raises a problem with too many ramifications for discussion here. In the provincial museum, however, education might provide a channel for the further assistance from public funds for which a plea has been put forward. Such matters will no doubt come within the purview of the promised public inquiry.

\section{FUNDAMENTAL CONCEPTS OF ELECTROMAGNETICS}

\section{Electromagnetics}

A Discussion of Fundamentals. By Prof. Alfred O'Rahilly. Pp. xii +884 . (London, New York and Toronto: Longmans, Green and Co., Ltd. ; Cork : Cork University Press, 1938.) 42s. net.

HOWEVER gratifying the remarkably rapid progress of experimental science and its practical applications during the last few decades may appear, the immense accumulation of new facts and hypotheses has tended greatly to confuse rather than to elucidate our fundamental concepts, and the edifice of science is becoming like a Tower of Babel in which hosts of skilled workers are busily engaged on their several portions but without plan or architect, and are becoming so divided by specialization as scarcely to be able to understand one another. To such an extent has this confusion grown that we seem to be reverting to pre-Newtonian scholasticism, and many modern men of science are now adopting the speculative and metaphysical modes of thought and expression against which science had to struggle for its very existence in its infancy; so that although humanity is more and more amazed at the achievements of science, it is losing confidence in it as a trustworthy interpreter of natural phenomena and as a guide to human progress.

There is therefore urgent need for a comprehensive review of our fundamental concepts, and Prof. O'Rahilly deserves our cordial thanks and admiration for the energy, skill, and courage with which he has undertaken this formidable task. Within the space available for this review, it is impossible to do more than indicate the immense field covered in this large volume, one of the most interesting and valuable features of which is the collection of quotations from the greatest authorities which reveal the large divergences of opinion which have always existed between them, even when agreement on most fundamental principles was supposed to prevail.

The majority of students, at least in Great Britain, have been brought up on the Maxwellian theory, involving the Faraday concepts of electric and magnetic fields in a medium, and are now being converted to the doctrine of relativity; but the author reminds us of the great body of theory built up by the Continental physicists, Poiss on, Gauss, Ampère, Neumann, Riemann, Weber and Lorenz, and their successors, Voight, Liénard, Schwarzschild and Ritz, based on action at a 